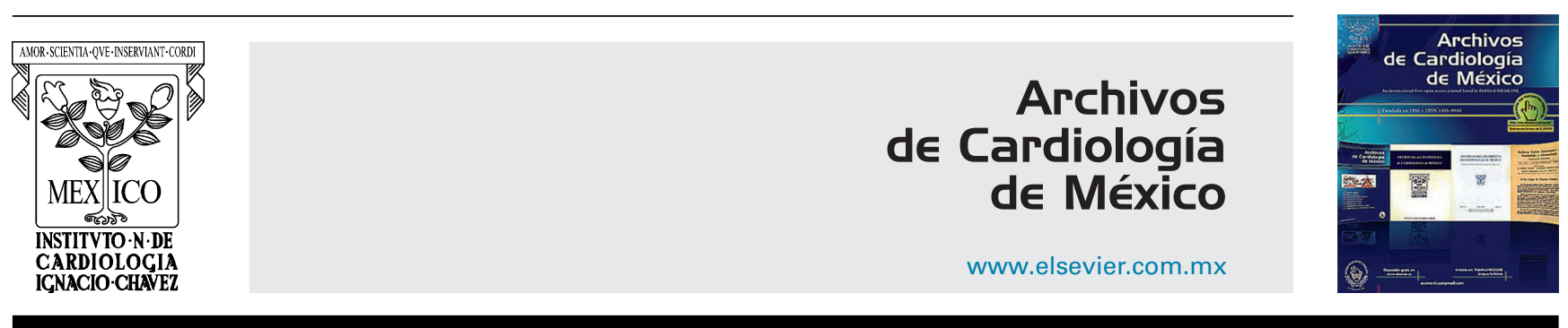

CLINICAL RESEARCH

\title{
Multicomponent exercise decreases blood pressure, heart rate and double product in normotensive and hypertensive older patients with high blood pressure
}

\author{
Hélio José Coelho-Júnior ${ }^{a, *}$, Ricardo Yukio Asano ${ }^{b}$, Ivan de Oliveira Gonçalvez ${ }^{c}$, \\ Cayque Brietzke $^{\mathrm{b}}$, Flávio Oliveira Pires ${ }^{\mathrm{b}}$, Samuel da Silva Aguiar ${ }^{\mathrm{d}}$, \\ Daniele Jardim Feriani ${ }^{a}$, Erico Chagas Caperuto ${ }^{\mathrm{e}}$, Marco Carlos Uchida ${ }^{\mathrm{a}}$, \\ Bruno Rodrigues $^{a}$
}

\footnotetext{
a Department of Adapted Physical Activity (DEAFA), School of Physical Education, University of Campinas, Av. Érico Veríssimo, 701. Cidade Universitária "Zeferino Vaz", Barão Geraldo, Campinas, SP, Brazil

b School of Arts, Sciences and Humanities, University of São Paulo, Rua Arlindo Béttio, 1000 - Ermelino Matarazzo, São Paulo, SP, Brazil

' Center of Health Sciences, University of Mogi das Cruzes, Av. Dr. Cândido Xavier de Almeida Souza, 200, Mogi das Cruzes, SP, Brazil

d School of Physical Education, Catholic University of Brasília, QS 0701 - Águas Claras, Brasília, DF, Brazil

e Human Movement Laboratory, São Judas Tadeu University (USJT), São Paulo, SP, Brazil
}

Received 19 October 2017; accepted 22 January 2018

\section{KEYWORDS}

Physical exercise;

Hypertension;

Older people;

Obesity;

Brazil

\begin{abstract}
Objective: The present study aimed to investigate the effects of a 6-month multicomponent exercise program on blood pressure, heart rate, and double product of uncontrolled and controlled normotensive and hypertensive older patients.

Methods: The study included 183 subjects, 97 normotensives, of which 53 were controlled normotensives (CNS), and 44 uncontrolled normotensives (UNS), as well as 86 hypertensives, of which 43 were controlled hypertensives (CHS), and 43 uncontrolled hypertensives (UHS). Volunteers were recruited and blood pressure and heart rate measurements were made before and after a 6-month multicomponent exercise program. The program of physical exercise was performed twice a week for 26 weeks. The physical exercises program was based on functional and walking exercises. Exercise sessions were performed at moderate intensity.

Results: The results indicated that UHS showed a marked decrease in systolic $(-8.0 \mathrm{mmHg})$, diastolic $(-11.1 \mathrm{mmHg})$, mean $(-10.1 \mathrm{mmHg})$, and pulse pressures, heart rate $(-6.8 \mathrm{bpm})$, and double product $(-1640 \mathrm{bpm} \mathrm{mmHg})$, when compared to baseline. Similarly, diastolic $(-5.5 \mathrm{mmHg})$ and mean arterial $(-4.8 \mathrm{mmHg})$ pressures were significantly decreased in UNS.
\end{abstract}

\footnotetext{
* Corresponding author at: Applied Kinesiology Laboratory, School of Physical Education, University of Campinas Avenida Érico Veríssimo, 701-Cidade Universitária "Zeferino Vaz", Barão Geraldo, CEP 13.083-851, Campinas, State of São Paulo, Brazil.

E-mail address: coelhojunior@hotmail.com.br (H.J. Coelho-Júnior).
} 


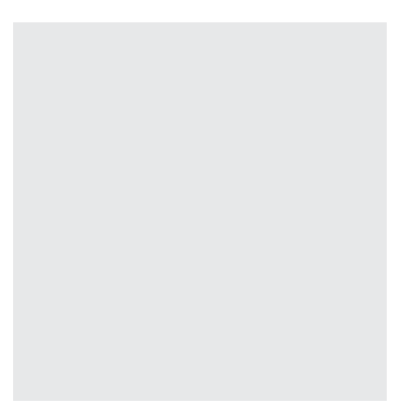

\section{PALABRAS CLAVE}

Ejercicio físico; Hipertensión; Personas mayores; Obesidad; Brasil
Concomitantly, significant changes could be observed in the body mass index $\left(-0.9 \mathrm{~kg} / \mathrm{m}^{2}\right.$; $\left.-1.5 \mathrm{~kg} / \mathrm{m}^{2}\right)$ and waist circumference $(-3.3 \mathrm{~cm}$; only UHS) of UNS and UHS, which may be associated with the changes observed in blood pressure.

Conclusions: In conclusion, the data of the present study indicate that a 6-month multicomponent exercise program may lead to significant reductions in blood pressure, heart rate, and double product of normotensive and hypertensive patients with high blood pressure values. (C) 2018 Instituto Nacional de Cardiología Ignacio Chávez. Published by Masson Doyma México S.A. This is an open access article under the CC BY-NC-ND license (http://creativecommons. org/licenses/by-nc-nd/4.0/).

El ejercicio multicomponente disminuye los parámetros hemodinámicos en pacientes ancianos normotensos e hipertensos no controlados

\begin{abstract}
Resumen
Objetivo: El presente estudio tuvo como objetivo investigar los efectos de un programa de ejercicios multicomponente de 6 meses sobre la presión arterial, la frecuencia cardíaca y el doble producto de pacientes mayores hipertensos y normotensos (incontrolados y controlados). Método: 183 sujetos, 97 normotensos - 53 normotensos controlados (SNC) y 44 normotensos no controlados (SNU) - y 86 hipertensos - 43 hipertensos controlados (CHS) y 43 hipertensos no controlados (UHS) -, fueron reclutados y sometidos a evaluaciones (presión arterial y frecuencia cardíaca) antes y después de un programa de ejercicios multicomponente de 6 meses. El programa de ejercicio se realizó dos veces por semana durante 26 semanas. El programa de ejercicios físicos se basó en ejercicios funcionales y de caminar. Las sesiones de ejercicio se realizaron a intensidad moderada.

Resultados: Los resultados indicaron que UHS presentó una marcada disminución en presión sistólica $(-8.0 \mathrm{mmHg})$, diastólica $(-11.1 \mathrm{mmHg})$, media $(-10.1 \mathrm{mmHg})$ y de pulso, frecuencia cardíaca $(-6.8 \mathrm{lpm})$ y doble producto $(-1640 \mathrm{lpm} \mathrm{mmHg})$ cuando se compara con la línea base. De manera similar, las presiones diastólica $(-5.5 \mathrm{mmHg})$ y arterial media $(-4.8 \mathrm{mmHg})$ se redujeron significativamente en los SNU. Concomitantemente, fue posible observar alteraciones significativas en el índice de masa corporal $\left(-0.9 \mathrm{~kg} / \mathrm{m}^{2} ;-1.5 \mathrm{~kg} / \mathrm{m}^{2}\right)$ y circunferencia de cintura $(-3.3 \mathrm{~cm}$, solo UHS) de UNS y UHS, lo que puede estar asociado con los cambios observados en la presión arterial.

Conclusiones: En conclusión, los datos del presente estudio indican que un programa de ejercicio multicomponente de 6 meses puede provocar reducciones significativas en la presión arterial, frecuencia cardíaca y doble producto de pacientes normotensos e hipertensos con valores de presión arterial alta.

(C) 2018 Instituto Nacional de Cardiología Ignacio Chávez. Publicado por Masson Doyma México S.A. Este es un artículo Open Access bajo la licencia CC BY-NC-ND (http://creativecommons. org/licenses/by-nc-nd/4.0/).
\end{abstract}

\section{Introduction}

The worldwide projections indicate an exponential increase in the elderly population in the next 40 years. ${ }^{1}$ Indeed, currently, older adults represent about $15 \%$ of the world's population, while this figure is expected to reach $30 \%$ by 2050. ${ }^{1}$

The aging process is a continuous phenomenon accompanied by alterations in some physiological systems (e.g., cardiovascular, skeletal muscle, metabolism), collaborating on the development of geriatric syndromes and chronic diseases. ${ }^{2-4}$ Hypertension is one of the most prevalent diseases in older people, affecting more than $70 \%$ of this population. ${ }^{5}$ The main concern about this disease is its poor prognosis because patients with high blood pressure demonstrate an increased risk for stroke (i.e., hemorrhagic and ischemic) and myocardial infarction. ${ }^{5,6}$ Moreover, a recent World Health Organization report established hypertension as the main risk factor for cardiovascular and overall death. ${ }^{6}$

Guidelines widely indicate physical exercise as a complementary practice in the management of blood pressure values in hypertensive patients since this tool may collaborate with the control of blood pressure and associated risk factors (e.g., obesity, insulin resistance, diabetes). ${ }^{7,8}$ In this sense, systematic reviews and meta-analytic regressions have demonstrated that aerobic and resistance (i.e., dynamic and isometric) training programs, can elicit significant decreases in the blood pressure values of hypertensive patients. ${ }^{9,10}$ However, the impact of other regimes of physical exercise on the hemodynamic parameters of hypertensive patients remains unclear. 
Recently, multicomponent exercise program (MCEP) has been suggested as a potential exercise design for physical exercise programs. ${ }^{11}$ The design of this kind of exercise is attractive due to its ability to combine different modalities of exercise (e.g. aerobic, resistance, stretching, balance) in the same exercise session or routine, thereby not requiring sessions with long duration while developing several physical capacities and skills. ${ }^{11}$ This feature of MCEP is especially important because hypertensive patients avoid very time-consuming physical exercise programs, possibly collaborating with the lack of adherence to the treatment in this population. ${ }^{12}$

Currently, just a few studies have been designed to study the effects of MCEPs on blood pressure values of hypertensive and normotensive elderly people. ${ }^{13}$ Furthermore, the few available relevant published data are based on experiments performed with low-sample sizes and using non-blinded methods to blood pressure assessment. ${ }^{13}$

It is worth mentioning, that the findings of de Moraes et al. ${ }^{13}$ suggest that the higher the blood pressure levels before the beginning of the MCEP, the greater the reduction in response to the physical stimulus ${ }^{13}$; indicating that volunteers with high blood pressure levels (uncontrolled) may present larger decreases in blood pressure values when compared to those with controlled blood pressure levels. Nevertheless, probably because of small sample size, volunteers were not divided and reanalyzed to test this hypothesis.

Therefore, the present study aimed to investigate the effects of a 6-month MCEP on blood pressure, heart rate and double product of normotensive and hypertensive elderly patients with normal (controlled) and high (uncontrolled) systolic blood pressure values.

\section{Methods}

The present investigation has a Quasi-Experimental design, which aimed to determine the effects of a 6-month MCEP on blood pressure, heart rate, and double product of normotensive and hypertensive elderly patients with normal (controlled) and high (uncontrolled) systolic blood pressure values. Therefore, blood pressure and heart rate were measured before and after the 6-month MCEP.

All volunteers signed the informed consent form and completed all measurements. This study was approved by the Research Ethics Committee of the University of Campinas under protocol number 835.733. This study was developed in accordance with the Declaration of Helsinki and according to Resolution 196/96 of the National Health Council.

\section{Subjects}

A total of 183 subjects, 97 normotensives (NTS) and 86 hypertensives (HTS), were recruited by convenience from two specialized public community health centers for older adults in a town of São Paulo city metropolitan area, in southeastern Brazil.

Eligibility criteria for this study were based on the presence of a clinical diagnosis of hypertension or not, and aged $\geq 60$ years. Patients of both sexes were accepted in the study. Patients who presented changes of antihypertensive medication in the past 6 months prior to inclusion in the study, a clinical diagnosis of cardiovascular (i.e., acute myocardial infarction, stroke, peripheral arterial disease, and transient ischemic disease), metabolic (i.e., diabetes mellitus type । or ॥), pulmonary disease (i.e., emphysema), neurological and/or psychiatric disease (i.e., Parkinson's or Alzheimer's disease), skeletal muscle disorders, comorbidities associated with greater risk of falls, recent history of smoking or alcohol abuse, and engagement in physical exercise training programs (three sessions per week) in the past 6 months prior to inclusion in the study were excluded. We also excluded participants who were prescribed hormone replacement therapy and/or psychotropic drugs.

Initially, the volunteers were subdivided into normotensive and hypertensive groups according to the clinical diagnosis of hypertension. Subsequently, volunteers were subdivided into four groups: (a) controlled normotensive patients (CNS); (b) uncontrolled normotensive patients (i.e., undiagnosed hypertensive patients; UNS); (c) controlled hypertensive patients (CHS); and (d) uncontrolled hypertensive patients (UHS). The division was based on the median values of systolic blood pressure $(\geq 129 \mathrm{mmHg})$. Therefore, patients with systolic blood pressure $\geq 129 \mathrm{mmHg}$ were allocated into the uncontrolled groups (i.e., UNS and UHS). On the other hand, patients with systolic blood pressure $<129 \mathrm{mmHg}$ were allocated into the controlled groups (i.e., CNS and CHS). It should be stressed that although the volunteers allocated into the UNS group did not present a clinical diagnosis of hypertension, the blood pressure values presented by them cannot be considered normal, since these values are higher than the defined cutoffs (uncontrolled) ${ }^{14}$ and, consequently, associated with an elevated cardiovascular risk. Therefore, these volunteers were considered as undiagnosed hypertensive patients.

Since both healthcare centers serve a large number of patients, and the medical team (i.e. nurse, physician and physical educator) is of limited size, the pathological conditions were simply recorded by the head physician and head nurse of each center. A specialist (i.e., cardiologist) who was not affiliated to and was outside the center then made the diagnosis of hypertension, according to the guidelines. ${ }^{14}$ In summary, before the participants began the activities in the centers where they were recruited, a medical consultation was conducted, and an extensive list of medical exams was required (e.g., chemistry panel, complete blood count, hormones quantification, blood pressure). If the patient showed any signal of hypertension, such as high blood pressure levels during the first visits to the centers, it was invited to measure blood pressure levels, at least, three times, during different periods of the day at home. If his/her blood pressure remained elevated, he/she was referred to a cardiologist. After being submitted to a specific medical consultation (i.e., cardiologist) and perform all specific exams (i.e., 24-h ambulatory blood pressure monitoring, home blood pressure), ${ }^{14}$ the patient returned to the center with a letter signed by the specialist confirming or not the diagnosis of hypertension. The criteria adopted to hypertension diagnosis (i.e., stage 1) proposed by the Brazilian Society of Cardiology was based on systolic blood pressure values among $140-159 \mathrm{mmHg}$ and/or diastolic blood pressure values among $90-99 \mathrm{mmHg} .{ }^{14}$ The final diagnosis was signed by the head-physician of the center. The records were 
updated every 6 months, and the volunteers of the present study were recruited one week after the last update.

\section{Evaluations}

All volunteers were instructed to refrain from any exhausting physical activity for a period of $96-\mathrm{h}$ before, and drinking alcoholic and caffeinated beverages 24-h before testing. Although alimentary ingestion was not controlled, subjects were instructed to maintain their food intake during the study period. Baseline evaluations (i.e., pre) were performed 5 days (i.e., $120 \mathrm{~h}$ ) before the beginning of the MCEP. Likewise, the final evaluations were performed on the fifth day after the last exercise session.

\section{Morphological measurements}

A weight scale with a Filizola ${ }^{\circledR}$ (Brazil) stadiometer was used to measure body mass $(\mathrm{kg})$ and height $(\mathrm{cm})$. The body mass index was determined by using the formula body mass $(\mathrm{kg}) /$ height $\left(\mathrm{m}^{2}\right)$. An anthropometric tape (flexible and inextensible) (Sanny ${ }^{\circledR}$, Brazil) was used to obtain all measurements (i.e., waist circumference, hip circumference, and neck circumference). Participants remained in a standing position, head held erect, eyes forward, with the arms relaxed at the side of the body, feet kept together, wearing light clothes. The waist circumference was assessed at the mid-point between the last floating rib and the highest point of the iliac crest. Hip circumference was evaluated at the highest point of the buttocks. Neck circumference was measured right above the cricoid cartilage and perpendicular to the long axis of the neck. ${ }^{15}$ All the subjects were evaluated twice, and the higher value was used for analysis.

\section{Blood pressure and heart rate assessment}

The procedures for blood pressure measurement were adapted from the vII Joint National Committee on Prevention, Detection, Evaluation, and Treatment of High Blood Pressure. ${ }^{7}$ In summary, volunteers remained in a sitting position on a comfortable chair for $15 \mathrm{~min}$ in a quiet room. After this period, an appropriate cuff was placed at approximately the midpoint of the upper left arm (heart level). An automatic, noninvasive, and validated ${ }^{16}$ arterial blood pressure monitor (Microlife-BP 3BT0A, Microlife, Widnau, Switzerland) was used to measure systolic blood pressure, diastolic blood pressure, and heart rate. During blood pressure recording, volunteers remained relaxed in the sitting position, with parallel feet at one shoulder width, both forearm and hands on the table, supinated hands, backs against the chair, without move or talk. The volunteer did not have access to blood pressure values during measurement. The evaluation lasted approximately $80 \mathrm{~s}$ and was performed three times with 1 min of rest among the measurements. The mean of three evaluations of each volunteer was used in the final analysis. Mean arterial and pulse pressures, and double product were evaluated according to the following equations: Mean arterial pressure $=$ [systolic blood pressure $+(2 *$ diastolic blood pressure $)] / 3$, Double Product $=$ systolic blood pressure ${ }^{*}$ heart rate, and Pulse Pressure $=$ systolic blood pressure - diastolic blood pressure. The size of the arm cuff was selected after measuring the arm circumference of each participant (Sanny, São Paulo, Brazil). All volunteers were evaluated within the first month after the update of the medical records.

\section{Multicomponent exercise program (MCEP)}

The MCEP was performed twice a week, on nonconsecutive days, during 26 weeks at the fitness center of an institutional center for elderly care and living, Poá, Brazil. The program was designed to offer exercises that would mimic activities of daily living gestures, thereby inducing neuromuscular adaptations to maintain or even improve the capacity to perform the activities of daily living. Each exercise session was composed of 12 different exercises stations. Each exercise session structure was defined by the sequence of one functional exercise followed immediately by a brief walk. Exercise sessions were composed of approximately $12 \mathrm{~min}$ of functional exercises, $24 \mathrm{~min}$ of walk and $12 \mathrm{~min}$ of rest. Each session of exercise was composed of approximately 50 patients. A physical trainer professional with larger expertise on exercise training to older people supervised all sessions. Volunteers were instructed to avoid the Valsalva maneuver during the performance of exercises.

The functional exercises were changed during the whole program. However, they always represented activities of daily living with a high necessity of the activity of the lower limbs, as, for example, stand and seat from the chair, pick up a weight off the floor and put on top of a structure, transfer a weight from one place to another. Functional exercises were also composed of balance and proprioception exercises, as one-leg stand. At most three balance and/or proprioception exercises were used in each session. To complete the list of physical exercises, upper limbs resistance exercises were added. Fig. 1 shows a representation of the functional (activities of daily living and balance) exercises and walk pathway generally used in the exercise sessions.

All functional exercises were performed for $1 \mathrm{~min}$, while brief walk was performed for 2 min. Thus, after the end of each functional exercise, volunteers should walk from one point to another $(30 \mathrm{~m})$, around a cone, come back to the initial line $(30 \mathrm{~m})$, and start the path again until complete the 2 -min. A rest interval of $60 \mathrm{~s}$ was adopted between the stations. A schematic representation of each station of exercise (functional exercise plus walk plus rest) can be observed in Fig. 2.

\section{Exercise intensity control}

The control of exercise intensity was accomplished by the rating of perceived exertion method using the adapted Borg scale (2001) (i.e. CR-10), ${ }^{17}$ which was used to ensure that volunteers performed the exercises in the aimed intensity. This scale is composed of eleven numbers (i.e., 0,1 , $2,3,4, \ldots$ ) and eight descriptors (i.e., rest; very, very easy; easy; moderate; somewhat hard; hard; very hard; maximal), which represents the perception of effort of the subject in front of an exercise load. The higher the reported number, the greater the sensation of effort. ${ }^{17}$ During the performance of functional - except for balance exercises - and resistance exercises, volunteers were instructed to 


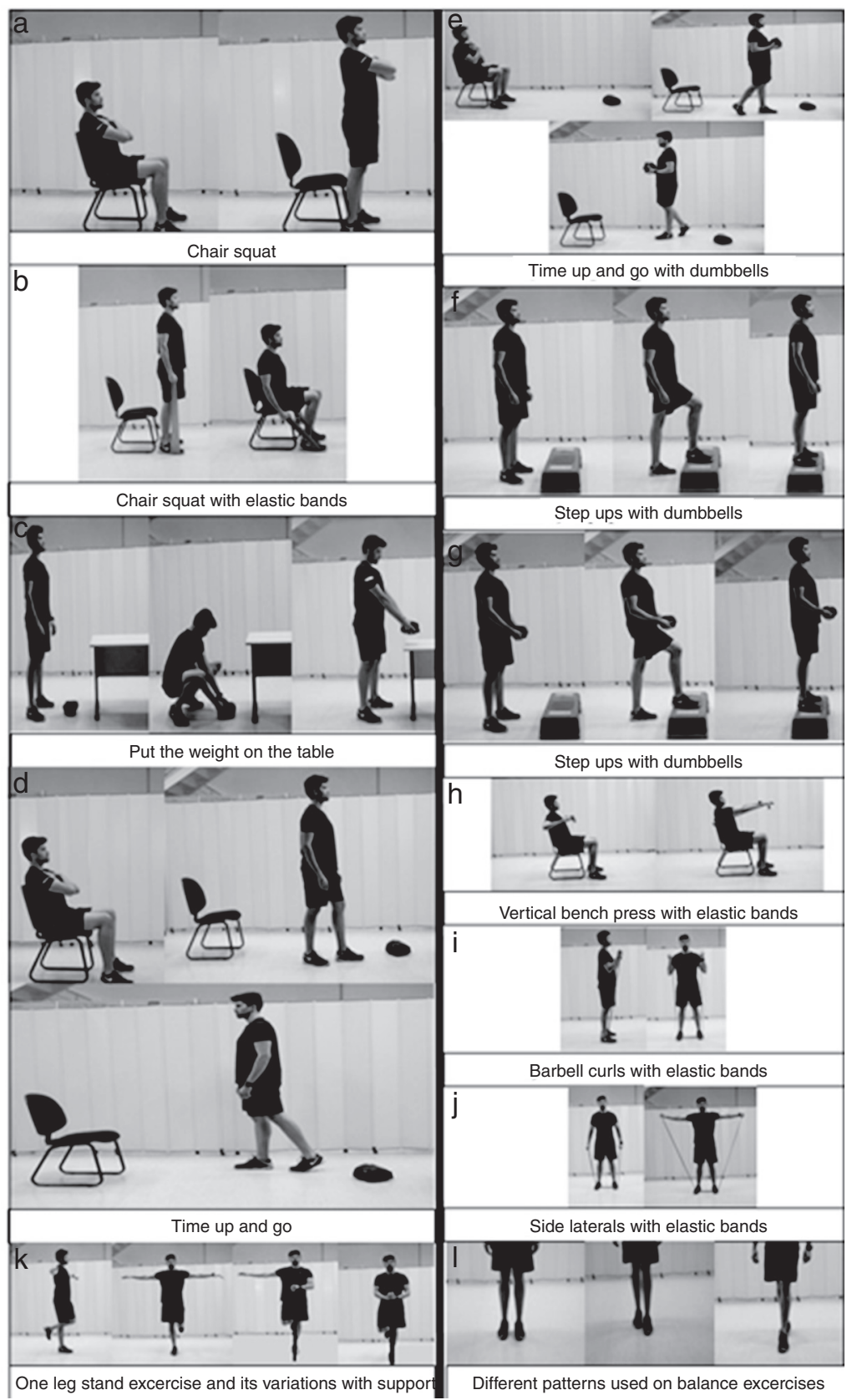

Figure 1 Some examples of the physical exercises performed during the MCEP. (a), (c), (d) and (f) show the functional exercises to lower limbs that mimic the activities of daily living. In turn, (b), (e) and (g) are the same exercises; however, with examples of approaches used to increase the load. Classical resistance exercises used in the MCEP for upper limbs are demonstrated in the (h), (i) and (j). Moreover, (k) and (l) show the balance exercises performed.

maintain the physical activity intensity in 3-5 - which represents moderate (i.e., 3), somewhat hard (i.e., 4), and hard (i.e., 5) descriptors. To that, a large picture of rating of perceived exertion scale (i.e., 4 meters high and 1.30 meters wide) was positioned on the wall in the gym's room. The increase in the exercise intensity was based on alterations in the cadence of the performance (i.e., faster), for functional exercises and walk. Moreover, for resistance exercises, volunteers could use elastic bands (EXTEX Sports, São Paulo, Brazil) and dumbbells to reach the intensity prescribed.

\section{Statistical analyses}

Normality of data was tested using the Kolmogorov-Smirnov test. Comparisons between the groups for age, weight, height, body mass index, hip circumference, waist circumference, neck circumference, systolic blood pressure, diastolic blood pressure, mean arterial pressure, heart rate, double product, and pulse pressure were performed using one-way analysis of variance followed by Tukey's posthoc test. Intragroup comparisons among the different periods (Pre, Post), were performed using Student- $t$-test for 


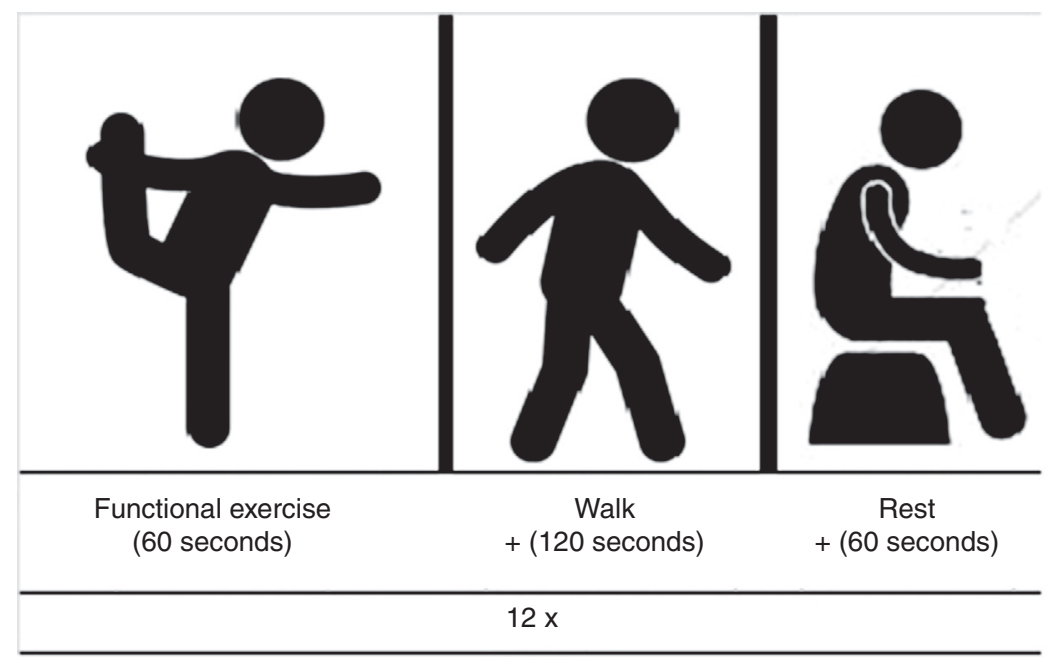

Figure 2 A schematic representation of each station of exercise (functional exercise plus walk plus rest).

dependent samples. Cohen's effect size $d$ was calculated to assess the magnitude of the results. The effect size was calculated according to Cohen's $d$ calculation, and considered as medium when values were between 0.2 and 0.5 , good when values between 0.5 and 0.8 , and large for values $\geq 0.8$. The level of significance was $5 \%(P<0.05)$ and all procedures were performed using the Statistical Package for the Social Sciences software (New York, USA).

\section{Results}

No adverse events occurred during the sessions of exercise or during any the evaluations. The subjects were not absent for more than three sessions of physical exercise. Adherence to the physical exercise program was $100 \%$ (0 dropouts). Volunteers did not report any changes in food intake and or in the number/class of medications during the study.

Table 1 shows the main characteristics of the older adults according to hypertension. It is possible to observe that NTS and HTS volunteers presented an overweight phenotype (body mass index $\geq 25 \mathrm{~kg} / \mathrm{m}^{2}$ ). The analysis of circumferences is in congruence with body mass index results and indicate that the volunteers were at high cardiovascular risk. Regarding mean systolic blood pressure, NTS $(115.5 \pm 10.1 \mathrm{mmHg})$ and HTS $(141.3 \pm 12.9 \mathrm{mmHg})$ volunteers presented values according to the cutoffs proposed by the Brazilian Society of Cardiology. ${ }^{14}$ When the hypothesis test was performed, higher body mass, body mass index, circumference values (i.e., waist, hip, and neck), blood pressure (i.e., systolic, diastolic, mean, and pulse pressure), heart rate, and double product were observed in HTS patients when compared to NTS volunteers. Age and height were not different between the groups.

The overall characteristics of the volunteers according to the median values of systolic blood pressure are shown in Table 2. UHS presented higher body mass, body mass index, circumference values (i.e., waist, hip, and neck), systolic and diastolic pressures, and double product when compared to CNS, UNS, and CHS. Mean arterial and pulse pressures, and heart rate were also elevated in UHS, whereas only when it was compared to CNS and CHS. Similarly, UNS (undiagnosed
Table 1 Characteristics of the older adults according to hypertension.

\begin{tabular}{|c|c|c|}
\hline Variables & NTS $(n=97)$ & HTS $(n=86)$ \\
\hline \multicolumn{3}{|l|}{ Subjects characteristics } \\
\hline Age (years) & $65.7 \pm 4.8$ & $65.9 \pm 5.7$ \\
\hline Body mass $(\mathrm{kg})$ & $67.6 \pm 14.4$ & $73.3 \pm 14.2 a$ \\
\hline Height $(m)$ & $1.54 \pm 0.2$ & $1.59 \pm 0.1$ \\
\hline Body mass index $\left(\mathrm{kg} / \mathrm{m}^{2}\right)$ & $26.9 \pm 5.2$ & $29.1 \pm 5.6 a$ \\
\hline Waist circumference $(\mathrm{cm})$ & $94.6 \pm 12.9$ & $100.6 \pm 13.8 a$ \\
\hline Hip circumference $(\mathrm{cm})$ & $103.2 \pm 10.9$ & $108.4 \pm 10.4 a$ \\
\hline Neck circumference (cm) & $35.8 \pm 3.1$ & $37.5 \pm 3.4 a$ \\
\hline \multicolumn{3}{|l|}{ Hemodynamic parameters } \\
\hline $\mathrm{SBP}(\mathrm{mmHg})$ & $115.5 \pm 10.1$ & $141.3 \pm 12.9 a$ \\
\hline $\mathrm{DBP}(\mathrm{mmHg})$ & $71.8 \pm 8.9$ & $83.4 \pm 9.7 a$ \\
\hline MAP $(\mathrm{mmHg})$ & $82.8 \pm 19.0$ & $102.7 \pm 8.9 a$ \\
\hline HR (bpm) & $73.7 \pm 12.7$ & $82.0 \pm 11.7 a$ \\
\hline $\mathrm{DP}$ (mmHg bpm) & $8160 \pm 2376$ & $11,601 \pm 2059 a$ \\
\hline $\mathrm{PP}(\mathrm{mmHg})$ & $41.9 \pm 13.3$ & $57.8 \pm 13.4 a$ \\
\hline
\end{tabular}

hypertensive patients) displayed higher blood pressure levels (i.e., systolic, diastolic, mean, and pulse pressure) and double product when compared to CNS and CHS. Lastly, CHS presented higher body mass index, and waist and hip circumferences when compared to CNS. These data suggest that the uncontrolled groups (i.e., UNS and UHS) presented higher blood pressure values when compared to controlled groups (i.e., CNS and CHS); while HTS groups (i.e., CHS and UHS) presented elevated fat mass when compared to NTS groups (i.e., CNS and UNS).

Table 3 shows the morphological parameters. CNS presented a significant increase in body mass index when compared to baseline. On the other hand, a significant decrease on body mass index $\left(-0.9 \mathrm{~kg} / \mathrm{m}^{2} ;-1.5 \mathrm{~kg} / \mathrm{m}^{2}\right)$ and waist circumference values $(-3.3 \mathrm{~cm})$ was observed in UNS 
Table 2 Comparison between the groups regarding the morphological and hemodynamic parameters.

\begin{tabular}{|c|c|c|c|c|}
\hline Variables & CNS $(n=53)$ & UNS $(n=44)$ & CHS $(n=43)$ & UHS $(n=43)$ \\
\hline \multicolumn{5}{|l|}{ Subjects characteristics } \\
\hline Age (years) & $65.3 \pm 5.2$ & $65.8 \pm 5.7$ & $67.1 \pm 5.4$ & $65.2 \pm 5.0$ \\
\hline Body mass $(\mathrm{kg})$ & $64.6 \pm 12.0$ & $65.4 \pm 12.4$ & $71.2 \pm 16.4$ & $81.1 \pm 11.4 a b c$ \\
\hline Height (m) & $1.52 \pm 0.3$ & $1.58 \pm 0.8$ & $1.57 \pm 0.6$ & $1.59 \pm 0.12$ \\
\hline Body mass index $\left(\mathrm{kg} / \mathrm{m}^{2}\right)$ & $25.6 \pm 4.4$ & $26.4 \pm 5.5$ & $28.4 \pm 5.7 a$ & $31.9 \pm 4.1 \mathrm{abc}$ \\
\hline Waist circumference $(\mathrm{cm})$ & $91.2 \pm 11.5$ & $93.0 \pm 12.5$ & $98.7 \pm 13.4 a$ & $107.8 \pm 9.1 \mathrm{abc}$ \\
\hline Hip circumference $(\mathrm{cm})$ & $100.7 \pm 9.8$ & $102.8 \pm 9.1$ & $106.2 \pm 11.4 a$ & $114.0 \pm 8.5 a b c$ \\
\hline Neck circumference $(\mathrm{cm})$ & $35.3 \pm 2.7$ & $35.6 \pm 3.3$ & $36.3 \pm 3.5$ & $39.4 \pm 2.4 a b c$ \\
\hline \multicolumn{5}{|l|}{ Hemodynamic parameters } \\
\hline $\mathrm{SBP}(\mathrm{mmHg})$ & $113.1 \pm 11.0$ & $137.6 \pm 11.3 \mathrm{ac}$ & $118.5 \pm 8.1$ & $145.0 \pm 13.4 a b c$ \\
\hline $\mathrm{DBP}(\mathrm{mmHg})$ & $70.5 \pm 10.0$ & $80.1 \pm 10.8 \mathrm{ac}$ & $73.3 \pm 7.2$ & $86.8 \pm 7.2 \mathrm{abc}$ \\
\hline $\mathrm{MAP}(\mathrm{mmHg})$ & $81.5 \pm 18.6$ & $99.3 \pm 9.1 \mathrm{ac}$ & $84.3 \pm 19.7$ & $106.2 \pm 7.3 \mathrm{ac}$ \\
\hline HR (bpm) & $73.4 \pm 9.0$ & $79.6 \pm 14.1$ & $74.1 \pm 16.2$ & $84.4 \pm 8.2 \mathrm{ac}$ \\
\hline $\mathrm{DP}(\mathrm{mmHg} \mathrm{bpm})$ & $7973 \pm 1971$ & $10,967 \pm 2254 a c$ & $8390 \pm 2804$ & $12,235 \pm 1636 a b c$ \\
\hline $\mathrm{PP}(\mathrm{mmHg})$ & $40.9 \pm 13.1$ & $57.4 \pm 13.4 \mathrm{ac}$ & $43.1 \pm 13.5$ & $58.1 \pm 13.5 \mathrm{ac}$ \\
\hline
\end{tabular}

Data are presented as mean \pm SD. CNS = normotensive patients with controlled hemodynamic parameters; UNS = normotensive patients with uncontrolled hemodynamic parameters; $\mathrm{CHS}=$ hypertensive patients with controlled hemodynamic parameters; UHS = hypertensive patients with uncontrolled hemodynamic parameters; $\mathrm{SBP}=$ systolic blood pressure; $\mathrm{DBP}=$ diastolic blood pressure; $M A P=$ mean arterial pressure; $\mathrm{HR}=$ heart rate; $\mathrm{DP}=$ double product; $\mathrm{PP}=$ pulse pressure; $\mathrm{a}=P<0.05$ vs $\mathrm{CNS} ; \mathrm{b}=P<0.05$ vs $\mathrm{HNS} ; \mathrm{c}=P<0.05$ vs $\mathrm{CHS}$.

Table 3 Morphological parameters of the exercise groups.

\begin{tabular}{|c|c|c|c|c|}
\hline & CNS & UNS & $\mathrm{CHS}$ & UHS \\
\hline & \multicolumn{4}{|c|}{ Body mass index $\left(\mathrm{kg} / \mathrm{m}^{2}\right)$} \\
\hline$\Delta$ & $0.3^{*}$ & $-0.9^{*}$ & 0.9 & $-1.5^{*}$ \\
\hline$P$ value & 0.01 & 0.003 & 0.40 & 0.07 \\
\hline \multirow[t]{2}{*}{ ES } & -0.09 (unclassifiable) & -0.17 (unclassifiable) & -0.13 (unclassifiable) & 0.31 (medium) \\
\hline & \multicolumn{4}{|c|}{ Waist circumference $(\mathrm{cm})$} \\
\hline$\Delta$ & 0.5 & -4.0 & 0.1 & $-3.3^{*}$ \\
\hline$P$ value & 0.84 & 0.34 & 0.53 & 0.09 \\
\hline \multirow[t]{2}{*}{ ES } & -0.04 (unclassifiable) & 0.21 (medium) & -0.00 (unclassifiable) & 0.28 (medium) \\
\hline & \multicolumn{4}{|c|}{ Hip circumference $(\mathrm{cm})$} \\
\hline$\Delta$ & -1.2 & -3.0 & -1.0 & -2.4 \\
\hline$P$ value & 0.88 & 0.82 & 0.57 & 0.41 \\
\hline \multirow[t]{2}{*}{ ES } & 0.11 (unclassifiable) & 0.20 (medium) & 0.08 (unclassifiable) & 0.25 (medium) \\
\hline & \multicolumn{4}{|c|}{ Neck circumference $(\mathrm{cm})$} \\
\hline$\Delta$ & -0.5 & -1.6 & 0.2 & -1.1 \\
\hline$P$ value & 0.94 & 0.66 & 0.63 & 0.11 \\
\hline ES & 0.11 (unclassifiable) & 0.26 (medium) & -0.05 (unclassifiable) & 0.19 (unclassifiable) \\
\hline
\end{tabular}

Data are presented as mean \pm SD. CNS = normotensive patients with controlled hemodynamic parameters; UNS = normotensive patients with uncontrolled hemodynamic parameters; $\mathrm{CHS}=$ hypertensive patients with controlled hemodynamic parameters; UHS = hypertensive patients with uncontrolled uncontrolled hemodynamic parameters; ES = Effect size.

* $P<0.05$ vs baseline.

and UHS, respectively, after the MCEP. No significant alterations were observed in CHS.

Blood pressure values, heart rate, and double product are shown in Table 4. UHS presented a marked decrease in systolic $(-8.0 \mathrm{mmHg})$, diastolic $(-11.1 \mathrm{mmHg})$, mean $(-10.1 \mathrm{mmHg})$, and pulse pressures, heart rate (-6.8 bpm), and double product $(-1640 \mathrm{bpm} \mathrm{mmHg})$ when compared to baseline. Similarly, diastolic $(-5.5 \mathrm{mmHg})$ and mean arterial $(-4.8 \mathrm{mmHg})$ pressures were significantly decreased in UNS. On the other hand, CNS presented a significant increase in systolic $(+5.2 \mathrm{mmHg})$ and pulse pressures $(+6.5 \mathrm{mmHg})$, heart rate $(+2.8 \mathrm{bpm})$ and double product $(+1012 \mathrm{bpm} \mathrm{mmHg})$ after 6 months.

\section{Discussion}

The present study was designed to evaluate the effects of a MCEP on blood pressure, heart rate, and double product of HTS and NTS elderly patients with controlled and 
Table 4 Hemodynamic parameters of the exercise groups.

\begin{tabular}{|c|c|c|c|c|}
\hline & CNS & UNS & $\mathrm{CHS}$ & UHS \\
\hline & \multicolumn{4}{|c|}{$\mathrm{SBP}(\mathrm{mmHg})$} \\
\hline$\Delta$ & $5.2^{*}$ & -2.9 & 4.9 & $-8.0^{*}$ \\
\hline$P$ value & 0.02 & 0.26 & 0.08 & 0.01 \\
\hline \multirow[t]{2}{*}{ ES } & -0.40 (medium) & 0.19 (unclassifiable) & -0.43 (medium) & 0.49 (medium) \\
\hline & \multicolumn{4}{|c|}{$\mathrm{DBP}(\mathrm{mmHg})$} \\
\hline$\Delta$ & 0.3 & $-5.5^{*}$ & 1.4 & $-11.1^{*}$ \\
\hline$P$ value & 0.93 & 0.005 & 0.26 & $<0.001$ \\
\hline \multirow[t]{2}{*}{ ES } & -0.03 (unclassifiable) & 0.42 (medium) & -0.18 (unclassifiable) & 1.32 (large) \\
\hline & \multicolumn{4}{|c|}{ MAP (mmHg) } \\
\hline$\Delta$ & 5.2 & $-4.8^{*}$ & 2.4 & $-10.1^{*}$ \\
\hline$P$ value & 0.07 & 0.03 & 0.18 & $<0.001$ \\
\hline \multirow[t]{2}{*}{ ES } & -0.35 (medium) & 0.41 (medium) & -0.11 (unclassifiable) & 1.39 (large) \\
\hline & \multicolumn{4}{|c|}{ HR (bpm) } \\
\hline$\Delta$ & $2.8^{*}$ & 1.1 & 4.3 & $-6.8^{*}$ \\
\hline$P$ value & 0.03 & 0.66 & 0.49 & 0.003 \\
\hline \multirow[t]{2}{*}{ ES } & -0.31 (medium) & -0.08 (unclassifiable) & -0.28 (medium) & 0.61 (good) \\
\hline & \multicolumn{4}{|c|}{$\mathrm{DP}(\mathrm{mmHg} \mathrm{bpm})$} \\
\hline$\Delta$ & $1012^{*}$ & -110 & 821 & -1640 \\
\hline$P$ value & 0.0004 & 0.64 & 0.34 & 0.0002 \\
\hline \multirow[t]{2}{*}{ ES } & -0.60 (good) & 0.05 (unclassifiable) & -0.28 (medium) & 0.89 (large) \\
\hline & \multicolumn{4}{|c|}{$\mathrm{PP}(\mathrm{mmHg})$} \\
\hline$\Delta$ & $6.5^{*}$ & 2.8 & 3.3 & 3.0 \\
\hline$P$ value & 0.001 & 0.36 & 0.21 & 0.61 \\
\hline ES & -0.52 (good) & -0.16 (unclassifiable) & -0.23 (medium) & -0.15 (unclassifiable) \\
\hline
\end{tabular}

Data are presented as mean \pm SD. CNS = normotensive patients with controlled hemodynamic parameters; UNS = normotensive patients with uncontrolled hemodynamic parameters; $\mathrm{CHS}=$ hypertensive patients with controlled hemodynamic parameters; UHS=hypertensive patients with uncontrolled hemodynamic parameters; $\mathrm{SBP}=$ systolic blood pressure; $\mathrm{DBP}=$ diastolic blood pressure; $\mathrm{MAP}=$ mean arterial pressure; $\mathrm{HR}=$ heart rate; $\mathrm{DP}=$ double product; $\mathrm{PP}=$ pulse pressure.

* $P<0.05$ vs baseline.

uncontrolled systolic blood pressure values. Findings of the present study indicate that a 6-month MCEP can elicit significant reductions in the blood pressure values of uncontrolled NTS and HTS patients. Concomitantly, significant changes on body mass index and waist circumference (only UHS) were observed in the uncontrolled groups, which may be associated with the reduced blood pressure values presented by the groups after the physical intervention.

To the best of our knowledge, just one experiment investigated the effects of a MCEP on blood pressure values of older HTS patients. In their study, de Moraes et al. ${ }^{13}$ observed a significant decrease in systolic $(-3.2 \mathrm{mmHg})$ and diastolic blood pressures $(-2.0 \mathrm{mmHg})$ after a 3 -month MCEP. However, researchers studied a small sample size $(n=36)$ and used a non-blinded method to blood pressure evaluation. ${ }^{13}$

It should be stressed, that de Moraes et al. ${ }^{13}$ observed that the higher the blood pressure levels before the beginning of the MCEP, the greater the reduction in response to the physical stimulus, indicating that volunteers with high blood pressure levels (uncontrolled) may present larger decreases in blood pressure values when compared to those with controlled blood pressure levels. Nevertheless, probably because of small sample size, volunteers were not divided and reanalyzed to test this hypothesis.
The present study confirms the findings of previous research. ${ }^{13}$ Indeed, UHS patients presented a significant decrease on systolic $(-8.0 \mathrm{mmHg})$, diastolic $(-11.1 \mathrm{mmHg})$, and mean $(-10.1 \mathrm{mmHg})$, arterial pressures, heart rate $(-6.8 \mathrm{bpm})$ and double product $(-1640 \mathrm{mmHg} b \mathrm{bm})$ after the MCEP. In addition, our findings add to the literature supporting the hypothesis that the beneficial effects of the MCEP on the cardiovascular system are not restricted to UHS patients since a significant decrease on diastolic $(-5.5 \mathrm{mmHg})$ and mean arterial $(-4.8 \mathrm{mmHg})$ pressures was observed in UNS patients.

The relation between baseline blood pressure levels and the magnitude of changes in the hemodynamic parameters after physical exercise has been widely studied in the literature. ${ }^{9,18}$ However, experiments have been exclusively performed based on aerobic and resistance exercises. Therefore, in addition to the findings of de Moraes et al., ${ }^{13}$ we showed that MCEPs may be an effective tool to elicit improvements in the cardiovascular system of patients with poorly controlled blood pressure, suggesting that this type of physical exercise may be an alternative to aerobic and resistance training protocols.

Indeed, exercise machines, dumbbells, and treadmills are associated with a high-cost and, consequently, are not attractive to compose public health programs aimed at 
promoting the health of older adults. On the other hand, we proposed a low-cost and easy to apply protocol of exercise. Nevertheless, much attention is required from the health professionals (e.g., physiotherapists and physical educators) responsible for the prescription of physical exercise during aerobic and resistance training protocols to avoid falls and injuries; while MCEP may be performed without treadmills, cyclergometers, and exercise machines, as was demonstrated in the current study.

Furthermore, it is worth mentioning that our resistance and functional components were based on activities of daily living commonly performed by older adults. This seems to be a better approach for elderly, at least, in the first weeks/months of exercise due to the standard of motor recruitment, avoiding long and disengaging periods of adaptation; collaborating with exercise performance, adherence, motivation, and safety. The utilization of elastic bands has also to be highlighted since they are portable, inexpensive, reliable, and its resistance (load) may be quantified in $\mathrm{kgf}(1 \mathrm{kgf}=1 \mathrm{~kg}) \cdot{ }^{19-21}$ Lastly, the use of elastic bands can meet the need to exercise machine, because evidence suggest similar morphofunctional adaptations after resistance training programs performed with machines or elastic bands. ${ }^{19-21}$

We are not able to explain the mechanisms responsible for decreased blood pressure and heart rate after the MCEP. However, recent meta-analytic data suggest that changes in body weight may collaborate with additional reductions in blood pressure values. ${ }^{9}$ In the current study, the marked decrease in blood pressure values of UNS and UHS volunteers was followed by a significant reduction in body mass index and waist circumference (just in UHS). On the other hand, CNS presented an increase in systolic blood pressure values $(+5.2 \mathrm{mmHg})$ accompanied by a superficial $(+0.3)$, but significant, increase in body mass index. Taken together, these data suggest that body composition may play a key role in the changes of blood pressure observed in the present study.

In the recent years, adipose tissue has gained notoriety due to the growing body of evidence that has recognized its critical role as an active tissue with endocrine and metabolic actions, which affects several physiological functions including glucose and lipid metabolism, thermogenesis, energy expenditure, inflammatory state, and cardiovascular homeostasis. ${ }^{22,23}$

The crosstalk between the white adipose tissue and the organic system is mediated by chemical mediators called as adipokines (e.g., leptin, resistin, visfatin, apelin, adiponectin). ${ }^{22,23}$ Interestingly, most adipokines have been associated with the genesis and development of cardiovascular risk factors, such as the synthesis and release of reactive oxygen species and pro-inflammatory cytokines, endothelial dysfunction, impaired nitric oxide bioavailability, and atherosclerosis. ${ }^{22,23}$ On the other hand, adiponectin has shown opposite effects when compared to other adipokines, since its actions are predominately antiatherogenic and anti-inflammatory. ${ }^{22,23}$

Thus, it is possible to infer that the weight loss observed in UNS and UHS groups may have collaborated with the reductions in blood pressure values through a phenomenon adipokine-dependent, restoring endothelial homeostasis. ${ }^{22,24}$ However, this hypothesis seems to be limited, since the low frequency ( $2 \mathrm{~d} /$ week) and volume of the aerobic component used in our MCEP were unlikely to elicit significant metabolic effects and, consequently, changes in the body mass index.

Moreover, an increased body mass index was observed in the CNS volunteers after 6 months. Our data do not allow strong inferences regarding this phenomenon. It should be stressed that it does not necessarily reflect an increase in body fat mass because evidence have demonstrated a significant increase in skeletal muscle mass of older people after MCEPs. ${ }^{25}$ Therefore, findings of the present study may indicate that MCEPs are not effective to prevent the increase of blood pressure values in CNS; but the lack of two sedentary NTS and HTS control groups limit our inferences. Indeed, it should be assumed that the lack of a control group is the main weakness of the present experiment and future studies must contemplate this issue to confirm and expand the knowledge about the current data.

Yet, although the volunteers have not reported any changes in food intake, self-report food consumption is not the gold standard approach for identifying changes in eating habits and a more accurate evaluation method (e.g., dietary recall) should be used in future studies. Nevertheless, older adults commonly present taste desensitization, which causes changes in the amount of seasoning in food, mainly sodium, a fundamental element in the homeostasis of hemodynamic parameters. ${ }^{26,27}$ Once increased, sodium leads to increase in blood pressure values, but not necessarily in body mass. ${ }^{26,27}$

Lastly, future studies must also include the evaluation of other domains, such as physical function (i.e., aerobic capacity), allowing a better understanding of the effects of MCEP in HTS older adults.

\section{Conclusions}

In conclusion, data of the present study indicate that a 6-month MCEP may elicit significant reductions in blood pressure, heart rate and double product of normotensive and hypertensive patients with high blood pressure values.

\section{Funding}

This research received no specific grant from any funding agency in the public, commercial, or not-for-profit sectors.

\section{Conflicts of interests}

The authors declare that they have no conflict of interest.

\section{Acknowledgements}

The authors are grateful to the Conselho Nacional de Desenvolvimento Científico e Tecnológico for the scholarships to Hélio José Coelho Júnior and Ricardo Yukio Asano. Bruno Rodrigues had financial support from the Fundação de Amparo à Pesquisa do Estado de São Paulo (process $n$. 2017/21320-4) and Conselho Nacional de Desenvolvimento Científico e Tecnológico. The authors are also grateful to Daisy dos Reis and Flávio Romano, from the facility for older adults, and all researchers from the Research Group on 
Chronic-Degenerative Diseases of Mogi das Cruzes University (Grupo de Pesquisa em Doenças Crônico-Degenerativas da Universidade de Mogi das Cruzes - for their support.

\section{References}

1. United Nations. World population prospects: the 2015 revision. Key findings and advance tables. New York: United Nations; 2015.

2. Coelho Júnior HJ, Aguiar SDS, Gonçalves IDO, et al. Sarcopenia is associated with high pulse pressure in older women. J Aging Res. 2015.

3. Sampaio RAC, Sewo Sampaio PY, Yamada M, et al. Arterial stiffness is associated with low skeletal muscle mass in Japanese community-dwelling older adults. GGI. 2014;14(S1): 109-14.

4. Sewo Sampaio PY, Sampaio RAC, Coelho Júnior HJ, et al. Differences in lifestyle, physical performance and quality of life between frail and robust Brazilian community-dwelling elderly women. Geriatr Gerontol Int. 2016;16:829-35.

5. Go AS, Mozaffarian D, Roger VL, et al. Heart disease and stroke statistics - 2014 update. Circulation. 2014;129:28.

6. World Health Organization. Global health risks: mortality and burden of disease attributable to selected major risks. World Health Organization; 2009.

7. Chobanian AV, Bakris GL, Black HR, et al. The seventh report of the joint national committee on prevention, detection, evaluation, and treatment of high blood pressure: the JNC 7 report. JAMA. 2003;289:2560-71.

8. James PA, Oparil S, Carter BL, et al. 2014 evidence-based guideline for the management of high blood pressure in adults: report from the panel members appointed to the Eighth Joint National Committee (JNC 8). JAMA. 2014;311:507-20.

9. Cornelissen VA, Smart NA. Exercise training for blood pressure: a systematic review and meta-analysis. J Am Heart Assoc. 2013;2:e004473.

10. Carlson DJ, Dieberg G, Hess NC, et al. Isometric exercise training for blood pressure management: a systematic review and meta-analysis. Mayo Clin Proced. 2014;89:327-34.

11. Cadore EL, Rodríguez-Mañas $L$, Sinclair A, et al. Effects of different exercise interventions on risk of falls, gait ability, and balance in physically frail older adults: a systematic review. Rejuvenation Res. 2013;16:105-14.

12. Asano RY, Moraes NF, Oliveira VP, et al. Fatores que afetam o perfil sedentário em pacientes com hipertensão arterial sistêmica. Braz J Sci Mov. 2015;24:5-15.
13. Moraes WMD, Souza PR, Pinheiro MH, et al. Exercise training program based on minimum weekly frequencies: effects on blood pressure and physical fitness in elderly hypertensive patients. Braz J Phys Ther. 2012;16:114-21.

14. Sociedade Brasileira de Hipertensão. Sociedade Brasileira de Cardiologia, and Sociedade Brasileira de Nefrologia. vı Brazilian guidelines on hypertension. Arq Bras Cardiol. 2010;95.

15. Coelho Júnior HJ, Sampaio RAC, Gonçalvez IDO, et al. Cutoffs and cardiovascular risk factors associated with neck circumference among community-dwelling elderly adults: a cross-sectional study. Sao Paulo Med J. 2016;134:519-27.

16. Cuckson AC, Reinders A, Shabeeh H, Shennan AH, British Hypertension Society. Validation of the Microlife BP 3BTO-A oscillometric blood pressure monitoring device according to a modified British Hypertension Society Protocol. Blood Press Monit. 2002;7:319-24.

17. Foster C, Florhaug JA, Franklin J, et al. A new approach to monitoring exercise training. J Strength Cond Res. 2001;15:109-15.

18. Brito L, Queiroz A, Forjaz C. Influence of population and exercise protocol characteristics on hemodynamic determinants of post-aerobic exercise hypotension. Braz J Med Biol Res. 2014;47:626-36.

19. Uchida MC, Nishida MM, Sampaio RAC, et al. Thera-band ${ }^{\circledR}$ elastic band tension: reference values for physical activity. J Phys Ther Sci. 2016;28:1266.

20. Martins WR, de Oliveira RJ, Carvalho RS, et al. Elastic resistance training to increase muscle strength in elderly: a systematic review with meta-analysis. Arch Gerontol Geriatr. 2013;57:8-15.

21. Colado JC, Triplett NT. Effects of a short-term resistance program using elastic bands versus weight machines for sedentary middle-aged women. J Strength Cond Res. 2008;22:1441-8.

22. Yiannikouris F, Gupte M, Putnam K, et al. Adipokines and blood pressure control. Curr Opin Nephrol Hypertens. 2010;19:195.

23. Mattu HS, Randeva HS. Role of adipokines in cardiovascular disease. J Endocrinol. 2013;216:T17-36.

24. El Assar M, Angulo J, Rodríguez-Mañas L. Oxidative stress and vascular inflammation in aging. Free Radic Biol Med. 2013;65:380-401.

25. Cadore EL, Casas-Herrero A, Zambom-Ferraresi F, et al. Multicomponent exercises including muscle power training enhance muscle mass, power output, and functional outcomes in institutionalized frail nonagenarians. Age. 2014;36:773-85.

26. Ha SK. Dietary salt intake and hypertension. Electrolyte Blood Press. 2014;12:7-18.

27. Zhao D, Qi Y, Zheng Z, et al. Dietary factors associated with hypertension. Nat Rev Cardiol. 2011;8:456-65. 